\title{
Entrepreneurship in Jordanian public sector organisations
}

\section{Seif Athamneh*, Samir Al-Balas and Mohammad Taamneh}

Yarmouk University, Shafiq Irshidatst, Irbid 21163, Jordan

Email: seif.athamneh@yu.edu.jo

Email: samir.balas@yu.edu.jo

Email: taamneh@yu.edu.jo

*Corresponding author

\begin{abstract}
Entrepreneurship activities within the context of Jordanian public sector are relatively understudied compared with private sector within the Jordanian context. This study aimed to assess the perceptions of employees about entrepreneurship and its significance and applicability. This exploratory study used a structured questionnaire that was administered over three weeks to 181 Jordanian public sector employees selected using convenience sampling. We found that public sector employees perceived entrepreneurship positively and considered it to be very important. Moreover, the HR management frameworks played an integral role in enhancing and driving the level of entrepreneurship within the public sector. To our knowledge, this is the first time a study of this nature has been conducted within the public sector in Jordan. The result is critical and beneficial to policy makers and leaders in public institutions, helping them to develop a better entrepreneurial environment.
\end{abstract}

Keywords: entrepreneurship; Jordanian public sector; Jordan; privatisation.

Reference to this paper should be made as follows: Athamneh, S., Al-Balas, S. and Taamneh, M. (2018) 'Entrepreneurship in Jordanian public sector organisations', Int. J. Public Sector Performance Management, Vol. 4, No. 3, pp.267-285.

Biographical notes: Seif Athamneh is an Assistant Professor of Public Administration at the Yarmouk University - Irbid, Jordan. He served as an Assistant Office Manager at the Alpha HHS, Michigan, USA, in addition to his experience working with the International Medical Corps in Washington, DC, USA.

Samir Al-Balas is an Assistant Professor of Public Administration at the Yarmouk University - Irbid, Jordan. He was the Head of Public and Employee Health Department at the Herá Public Hospital - Mecca, Saudi Arabia. In addition, he worked as a Doctor of Dental Medicine at the Jordanian $\mathrm{MOH}$ - Irbid, Jordan.

Mohammad Taamneh is a Full Professor of Public Administration and the Dean of the Faculty of Economics and Administrative Sciences at the Yarmouk University - Irbid, Jordan. He was the President of the Jadara University-Jordan from 2010 to 2015. 


\section{Introduction}

Jordan enjoys an appropriate regulatory structure to support the development of enterprises. The legal system and strategies for enhancing transparency have resulted in the economy being supported by $98 \%$ of small and medium sized enterprises. Jordan is highly ranked in the Middle East as a destination for investments and entrepreneurship from domestic and foreign investors (JYES and Konrad Adenauer Stiftung, 2015). The government has dual purposes in promoting the business environment in the country. It acts as a rule maker and an entrepreneur through the regulatory commission and creates strategies for attracting foreign investments. In addition, the public has also become increasingly more demanding on the services provided by the public sector (Matthews, 2010). Through strategies such as privatisation and commercialisation, the public sector has become more exposed to market forces, increasing the need for innovation and entrepreneurship to improve performance.

This research assesses the state of entrepreneurship in the public sector in Jordan and specifically explores the factors that are perceived to be relevant for entrepreneurial development. It presents an empirical research study using a survey approach to assess the perceptions of managers and employees in government entities regarding entrepreneurship. The research makes use of a structured questionnaire to collect data on the main factors influencing public sector entrepreneurship in Jordan. It also evaluates the strategies that may be applied to improving the level of entrepreneurship in the country's public sector. Ultimately, the study aims to develop recommendations that can be applied to improve the outcomes for the public sector.

The main aim of the study is to assess the state of entrepreneurship in the Jordanian public sector. The specific objectives of the study are:

1 To assess the views of the employees about the importance of public sector entrepreneurship.

2 To find out the key aspects of innovation and entrepreneurship in the Jordanian public sector.

3 To evaluate the strategies adopted by public sector managers in enhancing innovation and entrepreneurship.

\section{Literature review}

Some people consider entrepreneurship as the initiation of new enterprises or businesses. However, it is broader than starting a new enterprise and often involves activities undertaken by individuals who are already in other organisations. Entrepreneurship can be described as being directly associated with innovation because it involves strategies designed to develop new ways of responding to the changes in their operating environment and increasing the domain of competence within specific markets (Kearney et al., 2008; Ramadani et al., 2017). The definition of entrepreneurship adopted by Zerbinati and Souitaris (2005) states that entrepreneurship involves the creation of economic activities that are new to the individual market. This approach is consistent with the views of Benz and Frey (2007) regarding the main elements of entrepreneurship, who argue that entrepreneurship is the development of new economic activities that may 
involve business models, products, or markets. Due to the diversity of the considerations adopted in understanding entrepreneurship, different types of entrepreneurs exist. Entrepreneurs can be institutional, corporate, or independent individuals with differing goals as well as expectations about the process. In effect, entrepreneurship is an important part of innovation and business development because it aids organisations in achieving the goal of responding to the needs of the market (Dana, 1993; Kearney et al., 2008). Entrepreneurs play a critical role in assessing the state of the market and their products and coming up with strategic new ways or products that can increase their competitiveness. The issue of competitiveness is not limited to provide sector organisations. Other types of organisations such as non-profit and public sectors require competitiveness on dimensions such as customer satisfaction, efficiency, and cost leadership (Dana and Dana, 2005). As a result, entrepreneurship is essential in all types of organisations.

According to Dana (1993), entrepreneurship has a very important role to play in the economic growth of a country. In his study, Dana (1993) discusses the effect of entrepreneurial development to a country's economic growth, and states that if a society values entrepreneurship, it is more likely that there will be policies developed around it because the government would likely have more buying and a positive attitude towards it. By contrast, if the government has no buy in, it is likely entrepreneurship will be highly regulated and minimised especially in the context of the public sector. This suggests that there is a critical role of governance in the level of entrepreneurship shown by the citizens of a country. Governments who value entrepreneurship and perceive it to be of high social and economic value are likely to develop policies and mechanisms to support; while others may see it as important but not invest so much in it with regards to promotion and support of entrepreneurial activities, and others may consider it a hindrance and undesirable and likely will not invest in promoting it. In his study, Dana (1993) uses examples of countries with different views on entrepreneurship and shows how this affected their economic growth and stability. He shows that countries who have high acceptance of entrepreneurship and do not intensely regulate rip the benefits such as high economic activity and productivity, and low unemployment and poverty statistics; while those who regulate and intervene in entrepreneurial, or are not active in promoting such activities, do not succeed.

Religion and culture have been highlighted as drivers of entrepreneurial activity within a society (Dana, 2009). Just as religion and culture shape behaviours, norms and beliefs, they can also shape the characteristic beliefs of entrepreneurship and how it is perceived. The value systems propagated by religion drive the orientation towards business activities and entrepreneurial ventures, for example, Dana (2009) gives various examples of religions and cultures that promote entrepreneurial activities and who outperform other religions and cultures in these activities. In the study, he discusses the entrepreneurial activities of Indians, Greeks, Hispanic catholic and non-Catholics, and Menmonites, and found that their success in business was directly related to their cultural value system about entrepreneurship and how they perceive it to benefit society, particularly the views towards capitalism. With regards to Islam, Dana (2009) asserts that it is a culture and religion least conducive to capitalism, but views capitalism in a holistic way as a mechanism to improve development for the community instead of individual. The principles of Islam assert the importance of hard work and activity in provisioning for one's family and the entire Muslim community, which drives entrepreneurship as part 
of the religion and culture (Ramadani et al., 2015). Therefore, entrepreneurship may take a collective form that is geared towards the achievement of communal goals.

An additional factor that can influence entrepreneurship within organisations is technology (Gergurri-Rashiti et al., 2017). Technology is considered one of the major drivers of innovation and contributors to overall firm performance because it allows for easy access and application of information. Most organisations use information to drive new products and services in response to market needs, and these drive innovation (Gergurri-Rashiti et al., 2017). For corporate entrepreneurship to be realised, individuals need to be able to assess information and external environment changes, and respond to these in an appropriate way. Therefore, appropriate use of technology can be an important driver of entrepreneurial activities within public sector organisations. It is unclear how much this is taking into consideration within public sector entities, but in private sectors, technology is a key driver of entrepreneurial activity. Productivity an essentially be increased by information technology, which can lead to high level success and innovation, particularly with regard to economic gains and profitability (Kearney et al., 2008; Ramadani et al., 2017).

\subsection{Link between private and public sector entrepreneurs}

Economies are made up of three major sectors: the public, private, and the social sector; which are interconnected and mutual, resulting in a higher standard of living for residents. Tosterud (2002) argues that a country that is weak in one of the sectors underachieves at least in one of the other two and this result in overall poor performance of the economy as a whole. As a result, the private and public sectors like non-profit institutions have to work towards improving their delivery of services and products continuously. Previous studies have identified some significant differences between public and private sectors (Morris and Jones, 1999; Kearney et al., 2009).

It is not very common within the public sector that entrepreneurship is encouraged or popularised (Hisrich and Al-Dabbagh, 2013). Some of the key dimensions of the similarities and differences in the two types of entrepreneurship identified in an earlier study by Morris and Jones (1999) include the primary motives, skills, attitude, approach towards risk, perceptions about failure and time orientation among others. Empirical efforts made to compare the state and definition of entrepreneurship in the private and public sector include a study by Kearney et al. (2009). In the study, Kearney and colleagues compared entrepreneurship in the two contexts. They defined public sector entrepreneurship as the process within public sector organisations that involves innovative activities such as proactivity, risk-taking, new administrative techniques, new technologies, services, and strategies for serving the public. They highlighted that in the public sector, entrepreneurship resulted in superior performance. Public sectors often outsource services from the private sector, they have stable sources of finance and highly bureaucratic in their approach to delivering services and products to the citizens, which generates a spirit of dependency instead of creativity, which reduces the likelihood of generating an entrepreneurial spirit within the organisation (Hisrich and Al-Dabbagh, 2013)

Most of the research in the field of entrepreneurship has focused on private sector organisations especially small and medium enterprises. The outcomes for these organisations are different from those of the public sector because of the differences in the motivations and goals of the involved parties (Kearney et al., 2009). In most cases, 
private sector innovation and entrepreneurship involves the development of new approaches to business problems. This is because of the external influences on private sector enterprises which need to adapt to rapidly changing markets to remain relevant and sustainable (Hisrich and Al-Dabbagh, 2013). The focus of these organisations in many cases is growth of the business because the investors are interested in ensuring that they can get the best outcomes for their shareholders. Because private sector organisations are interested in growing their market shares, profitability, and customer satisfaction, entrepreneurship involves strategies and developments that are geared towards improving the performance in the market (Currie et al., 2008). A major issue differentiating private and public sector entrepreneurship is the consideration of the key stakeholders and how they measure success. This influences the views that they hold regarding the risks involved in the process and the orientations about timelines for achievement of the set goals.

The research by Currie et al. (2008), Kearney et al. (2009) and Ramadani et al. (2017) indicate that innovation and entrepreneurship skills are critical in enhancing the performance of organisations. The focus of the organisations is on enhancing financial outcomes and efficiency. Kearney et al. (2008) proposed a model for public sector corporate entrepreneurship with emphasis on its influence on organisational performance, a proxy of growth, development and productivity, and influenced by several measures determined by the structure of the public sector and external environments. These factors included HR related factors and organisational culture internally within the organisation and socio-ecological factors such as politics and market changes that affect the organisation which all can affect the entrepreneurial initiatives or goals of the public sector organisation. We hypothesise that entrepreneurship enhances the productivity of individuals in the public sector just like they do in the private sector. However, there is little work polling public sector employees as to the views on the importance of entrepreneurship, and none as far as we know, in Jordan or other Middle Eastern countries. This leads to the first hypothesis.

Hypothesis 1 Employees of Irbid Governorate feel that entrepreneurship is important to their work and is a valuable factor of productivity.

\subsection{Public sector entrepreneurship}

According to Heinonen (2003), the private and public sectors are interconnected in different ways and both benefit from entrepreneurship. Changes in the society have increased the level of relationship between the two types of organisations resulting in higher levels of innovation in the public sector. The recession and the global financial crisis indicated significant weaknesses in the business environment as well as the public sector. The public sector faced increased problems in their operations due to the economic and ideological challenges. The ideological and other changes resulted in the need for the public-sector organisations to re-evaluate and renew their activities and improve how they address social needs (Radnor and Noke, 2012; Hisrich and Al-Dabbagh, 2013). The public-sector organisations have to come up with ways that make them more competitive and efficient in serving the needs of their customers.

The changes in demands for the public-sector organisations and increased competitiveness have resulted in the need for these organisations to seek the development of sustainable competencies. The issue of sustainable competencies is no longer limited 
to private sector organisations (see discussions in Hisrich and Al-Dabbach, 2013 on the challenges of entrepreneurship in government). The public sector is also required to focus on becoming more efficient with changes in many economies resulting in more market and customer orientation as well as accountability (Heinonen, 2003). According to Hisrich and Al-Dabbagh (2013) due to the stabilities, conservativeness and bureaucracy within government for example, there is not a strong focus on customer orientation, but instead on reaching specific objectives based on what the funding or financing activities that are determined politically. In Fact, in a recent study, Taamneh et al. (2017) shows that even the unperfect service delivery behaviour and work ethics of Jordanian university's administrators can be a challenge facing entrepreneurial behaviour, which ultimately means that entrepreneurial activity cannot be easily incited among employees.

An interesting development for many public-sector organisations is that, in many cases, the production of public goods and services is not maintained as a monopoly. This means there is room for competition from the private sector as well as partnerships. Collaborations involving private and public sector organisations have played a significant role in increasing competitiveness and changing the state of entrepreneurship. These issues have also made the private and public organisations more closely related. In the study by Heinonen (2003) undertaken using phone interviews to managers of public sector organisations, management involvement in the daily activities of teams was a significant motivator of intrapreneurship initiatives. The closeness of the manager to the team and the provision of resources were found to be critical elements of entrepreneurship success. Having management as an additional responsibility to others was ineffective because it did not give enough room to address entrepreneurship challenges. Another issue was that the pressure for change was more likely to be sparse in public sector organisations; hence the managers had to seek internal incentives and motivations to drive innovation and entrepreneurship (Spencer et al., 2005). Security and trust in the organisation and its values were also highlighted as significant in motivating people to engage in entrepreneurship. Individuals were found to be more committed to the growth of the organisation and themselves when they had higher views and perspectives about the security of their jobs. Target orientation and having effective targets for growth and development highlighted the roles of the employees and increased their engagement.

The views presented from the prior research on entrepreneurship in the public sector indicate that employee management strategies play a major role in enhancing motivation. This similar finding was shown by Taamneh et al. (2017) who show that work related ethics are also governed by employee management strategies. An organisation that takes care of its human resources and provides intrinsic motivation for them has a higher likelihood of tapping their entrepreneurial skills. This forms the basis for the second hypothesis of this research.

Hypothesis 2 Employee management and motivation strategies are the most effective in improving entrepreneurship in the Irbid Governorate.

\subsection{Innovation in the public sector}

A major issue in public sector innovations and entrepreneurship today is the commercialisation of intellectual property. It mostly involves the development of new knowledge on how to deliver improvements in effectiveness and efficiency for the 
government. Governments globally have faced increased need to enhance accountability and transparency through open data and releasing of public sector information. One of the main reasons for the increased transparency is concern for public rights. Managers in the public sector have also realised that releasing operational data is a source of entrepreneur activity (Matthews, 2010). Policies regarding the protection and sharing of intellectual property in different settings can influence the use of operational data from public sector organisations.

In the private sector, the drive towards performance improvement is a part of the organisational culture and goals (Ramadani et al., 2015). The public sector, on the other hand, presents a different environment where many attributes may inhibit innovation. The organisational and operational differences between public and private sector are extensive and they result in attributes that inhibit entrepreneurship. The main issue that sets the public sector apart from private organisations is the distinction between political and market orientations. Unlike the private sector, which responds to free market signals, the purpose of the public sector is determined by political forces that are external to the business (Spencer et al., 2005). The political forces affecting public organisations involve philosophies that can change with elections. The public-sector employees are also likely to face undue political influence that is difficult to prevent (Tosterud, 2002).

Other issues that are reported as influencing the entrepreneurship levels in public organisations include the lack of common pursuit or natural mechanism that correlates the goals of the employees with those of the politicians. Common incentives in the private sector such as stock options and profit sharing are not available in the public sector. The issue of commercialisation and privatisation of a public service function can be an incentive for improvement, but the monopoly position in most cases results in adverse outcomes (Spencer et al., 2005). This leads to insufficient competition and the performance of the public agencies is also affected by the professional competence, employee work ethic, and politically provided work resources. The work of Spencer et al. (2005) indicates that commercialisation and privatisation play a major role in promoting innovativeness and entrepreneurship in the public sector. A third research question, therefore, was to poll public sector employee views to determine whether they did indeed see privatisation as a positive factor in entrepreneurship. This forms the basis of the third hypothesis

Hypothesis 3 Privatisation is viewed as a positive factor in entrepreneurship among the employees of Irbid governorate.

The traditional approach to management in government agencies, which can be overly rule-bound, complicated and inflexible, is not conducive for innovation. Deregulation and privatisation have played a major role in creating a need for innovation and entrepreneurship in the public sector. Some of the reforms proposed in the sector with the aim of enhancing entrepreneurship include the implementation of a bottom-up employee empowerment program, customer driven processes, change management and flat hierarchies (Klein et al., 2009).

\subsection{Jordan context}

Jordan historically has an entrepreneurial history and culture as it was previously ruled by Greeks and Romans, as well as Nabataeans who were all entrepreneurial nations with 
highly business minded nature (Dana, 2000). To date, Jordan is driven largely by business activities which include agriculture. Here are also business incentives such as tax reductions which foster the development of small business in all of the industries, as well as facilitating small businesses to have links abroad and nationally (Dana, 2000). In addition, the country has established free zones for the manufacturing and storage of transient goods, which facilitates the development of small enterprises (Dana, 2000). The country is forward thinking in its business endeavours and proactively established mechanisms that facilitate entrepreneurship among the citizens.

Entrepreneurship among the citizens tend to follow down family lines where most entrepreneurs come from a family of self-employed people. According to Dana (200) Jordanians are not very keen to take risks and establish businesses, but through the support from the country, they are able to do so through numerous funding structures such as the Queen Alia Jordan Social und and making use of the investor reception centre and similar establishments, they are able to start small businesses. Moreover, to ensure the sustainable economic growth for the whole country, the policies of the country stipulate that all public shareholding companies must allocate $1 \%$ of annual profits to supporting vocational training, research and development to contribute towards skilling the workforce. Jordan is considered the 'Silicone valley of the middle east' largely due to the rapid development of information and communication technologies (ICT) which has led to increased productivity in all business sectors and economic growth (Caputo et al., 2016). In addition, there is strong support from royal family for entrepreneurship and skilling of the citizens in order to increase economic growth and productivity through innovation (Dana, 2000; Caputo et al., 2016). This focus on entrepreneurship development across all sectors and demographics is a critical aspect that makes Jordan unique among Middle Eastern countries. Thus, the view from our study that suggests that appropriate HR involvement and having appropriate motivators will increase entrepreneurial activity within the public sector is critical aspect here since most businesses will fall under the private sector. However, due to the requirements of Jordanian policy that these small businesses and enterprises contribute to the skilling of citizens, there is a contribution to the economic growth of the country. The question is how can these factors be translated to public sectors? How can ICT and other resources be applied within public sector contexts in order to facilitate entrepreneurial activity, because the responses from the participants is suggestive of the fact that they are aware of the importance of entrepreneurship but implementation is lagging.

\subsection{Research gap}

A major issue that comes up in the literature is the difference in the consideration of private and public sector entrepreneurship goals and strategies. The public sector has different interests and the strategies that may be applied in providing the required level of motivation for innovation vary. Public entities operate in environments that are not highly market oriented and the incentives available to them differ from those of the public sector. As a result, the management of public organisations has to respond to the changes in the operating environment by developing strategies for making the environment more attractive for entrepreneurship. The available literature on entrepreneurship has indicated that issues such as religion and culture influence the perceptions of individuals about risk and innovation (Audretsch et al., 2007). Religious beliefs and culture also influence the desirability of entrepreneurship and its nature (Ramadani et al., 2015). This, coupled with 
the need for reforms in the public sector, makes it essential to learn more about how it takes place.

\section{Methodology}

The study used a cross-sectional approach, sampling at a particular point in time to develop a snapshot of the situation (Creswell, 2014).

The population considered for the study included managers and subordinates of the Irbid governorate. The research was designed to understand how the employees and managers view entrepreneurship in the public sector as a whole. The sample was selected using quota sampling whereby equal proportions of managers and subordinates were selected in a convenience sampling approach because it was impossible to get the list of all employees for a random sampling.

The data collection instrument was a structured questionnaire that was designed using information gathered from different studies on the theories of public sector entrepreneurship (e.g., Short et al., 2009). The questionnaire consisted of 16 closed-ended questions that used Likert scale type ratings. The questionnaire was designed to take less than 15 minutes to complete. The instrument was pre-tested using a pilot study involving five employees to determine whether the questions were effectively understood. No issues were identified in the questions and the questionnaire was administered in the full study as it had been designed. The data collection involved talking with the different employees about the study and getting informed consent for their involvement. Any available employees were approached at the offices of the local government and provided with information about the study. Those indicating their willingness to engage in the study were asked to fill an informed consent form before getting the questionnaire. The informed consent form indicated the purpose of the study and how the information would be used. Respondents did not provide any personal identifiable information in the questionnaires to ensure their confidentiality. 200 questionnaires were given out to employees of the Irbid governorate.

The study utilised a descriptive approach to assess the data and for hypothesis testing. Descriptive statistics, mainly frequencies and cumulative frequencies were used to interpret the distribution of the participant's responses to the questionnaire. The data collected were entered from the questionnaires to the SPSS program for analysis.

Cronbach's alpha was utilised to measure correlation between the items of the survey and the construct that it intends to measure as advised by Andrew et al. (2011). Results showed that the reliability of the used scale is 0.87 , which is considered good.

\section{Results and discussion}

\subsection{Sample traits}

The response rate for the survey was $90.5 \%$ (181 returned questionnaires), with a balanced response between males (48.1\%) and females $(51.9 \%)$, Table 1 . In terms of the age distribution, the workforce can be considered to be relatively young with most employees in the age bracket of 26-35 years, with this age group making up 30.4\% of the sample followed by the age group 36-45 years which represented $27.1 \%$ of the sample; 
and only $13.8 \%$ of the respondents were below 25 years while $15.5 \%$ were above 55 years (Table 1).

Table 1 Age distribution of sample

\begin{tabular}{llll}
\hline Age & $N$ & \multicolumn{2}{c}{$\%$ Cumulative\% } \\
\hline Below 25 & 25 & 13.8 & 13.8 \\
$26-35$ & 55 & 30.4 & 44.2 \\
$36-45$ & 49 & 27.1 & 71.3 \\
$46-55$ & 24 & 13.3 & 84.5 \\
Over 55 & 28 & 15.5 & 100 \\
\hline
\end{tabular}

The sample was also diverse in terms of the level of experience that the respondents had in the civil service. Corroborating the youth of the sample participants, the majority of the sample population had under 5 years if working experience (Table 2). The largest group in the sample had $1-2$ years $(33.1 \%)$ and $2-5$ years $(24.9 \%)$ working experience, followed by the those who had 5-10 years working experience (16\%) and lastly those who had more than 10 years of experience $(12.7 \%) .34 .8 \%$ of the respondents were in lower management or supervisors with $30.9 \%$ in mid management. $21.5 \%$ of the respondents were in top management while $12.7 \%$ were at a subordinate level.

Table 2 Duration of tenure and experience

\begin{tabular}{lccc}
\hline Tenure & $N$ & $\%$ & Cumulative $\%$ \\
\hline$<1$ year & 24 & 13.3 & 13.3 \\
1-2 years & 60 & 33.1 & 46.4 \\
2-5 years & 45 & 24.9 & 71.3 \\
$5-10$ years & 29 & 16 & 87.3 \\
10 years + & 23 & 12.7 & 100 \\
\hline
\end{tabular}

\subsection{Importance of entrepreneurship}

The research sought to assess the views of the employees regarding the level of entrepreneurship in their organisations. $44.8 \%$ of the respondents in the sample indicated that the level of entrepreneurship in the organisation was low to very low, while. $27.1 \%$ of the respondents thought the level of entrepreneurship was medium. $28.1 \%$ of the respondents had positive views about the state of entrepreneurship within their organisation, rating high (17.1\%) to very high (11\%), Table 3 .

Table 3 Level of entrepreneurship in organisations

\begin{tabular}{lccc}
\hline Level & $N$ & $\%$ & Cumulative \% \\
\hline Very low & 24 & 13.3 & 13.3 \\
Low & 57 & 31.5 & 44.8 \\
Medium & 49 & 27.1 & 71.8 \\
High & 31 & 17.1 & 89 \\
Very high & 20 & 11 & 100 \\
\hline
\end{tabular}


The perceptions about the level of innovativeness differed slightly from the views about its relevance in the organisation. $50.3 \%$ of the respondents felt that innovation had a high to very high level of relevance in the organisation while $24.3 \%$ considered it low to very low; and $25.4 \%$ of the respondents were indifferent about the importance of innovation to the organisation (Table 4).

Table 4 State and relevance of entrepreneurship

\begin{tabular}{lccc}
\hline Rating & $N$ & $\%$ & Cumulative $\%$ \\
\hline Very low & 13 & 7.2 & 7.2 \\
Low & 31 & 17.1 & 24.3 \\
Medium & 46 & 25.4 & 49.7 \\
High & 53 & 29.3 & 79 \\
Very high & 38 & 21 & 100 \\
\hline
\end{tabular}

When asked their views on which employees were most effective in enhancing entrepreneurship in the public sector, the majority of the participants $(39.8 \%)$ indicated that experienced staff were most effective (Table 5).

Table 5 Characteristics of the most enterprising employees

\begin{tabular}{lccc}
\hline Characteristic & $N$ & $\%$ & Cumulative \% \\
\hline Young and middle aged & 30 & 16.6 & 16.6 \\
Experienced staff & 72 & 39.8 & 56.4 \\
Private sector background & 38 & 21 & 77.3 \\
Strong interest public service & 41 & 22.7 & 100 \\
\hline
\end{tabular}

Experienced employees were most frequently endorsed as the most innovative while those with strong interest in public service and those with a background in the private sector were considered the most innovative by $21 \%$ of the respondents. This result is supportive of hypothesis 1 because it shows that the employees value entrepreneurship and consider it to be one of the most important issues for improving service delivery.

Table 6 The main elements of entrepreneurship

\begin{tabular}{lccc}
\hline Element & $N$ & $\%$ & Cumulative \% \\
\hline Cost management & 39 & 21.5 & 21.5 \\
Service efficiency & 51 & 28.2 & 49.7 \\
Increasing PS reach & 37 & 20.4 & 70.2 \\
Process changes & 54 & 29.8 & 100 \\
\hline
\end{tabular}

From these responses, it seems age is not necessarily a significant factor in determining the level of entrepreneurship for public sector employees. The main elements of entrepreneurship in the public sector according to this sample were process changes and service efficiency, which were highlighted by $29.8 \%$ and $28.2 \%$ of the respondents respectively (see Table 6). The most common motivators of entrepreneurship in the organisation were rewards and incentives, followed by career development for the employees and improvement of services to the public. The three factors were cited as 
being the most important with employee rewards and incentives being the most commonly rated.

\subsection{Motivations of entrepreneurship}

The research also focused on the strategies that are adopted by the administrators of the public organisation to enhance entrepreneurship. The most important ways of enhancing public sector entrepreneurship were seeking creative employees through the hiring process (30.4\% of the respondents agree to this) and being open to novel ideas (27.6\% of respondents agree to this) (Table 7). Enhancing the commitment of the employees to the goals of the organisation was also significant as a way of improving entrepreneurship (Table 7).

Table 7 How management can enhance entrepreneurship

\begin{tabular}{lccc}
\hline Concept & $N$ & $\%$ & Cumulative \% \\
\hline Attracting creative people & 55 & 30.4 & 30.4 \\
Commitment of employees to organisational goals & 45 & 24.9 & 55.2 \\
Career development & 31 & 17.1 & 72.4 \\
Acceptance of radical ideas & 50 & 27.6 & 100 \\
\hline
\end{tabular}

Bureaucracy in public organisations is typically seen as a hindrance to entrepreneurial success; however, our study indicates a different view. The key element of public sector organisations that were cited as presenting major hindrances to entrepreneurship was misalignment of political and economic goals followed by the absence of adequate incentives for the organisation and the employees (Table 8). Bureaucracy was reported as a significant hindrance to entrepreneurship by $18.2 \%$ of the respondents. The absence of financial incentives was highlighted as a significant challenge and was the second most popular reason for poor performance of entrepreneurship in the public sector (Table 8).

Table 8 Hindrances to entrepreneurship

\begin{tabular}{lccc}
\hline Hindrance & $N$ & $\%$ & Cumulative \% \\
\hline Lack of incentives & 37 & 20.4 & 20.4 \\
Lack of profit goals & 33 & 18.2 & 38.7 \\
Misalignment of goals & 47 & 26 & 64.6 \\
Govt. interference & 31 & 17.1 & 81.8 \\
Bureaucracy & 33 & 18.2 & 100 \\
\hline
\end{tabular}

The main strategy that was reported as being the most effective in enhancing entrepreneurial development in organisations was employee incentives and rewards (Table 9). The employee and HR development programs that were considered most effective in enhancing entrepreneurship were contests involving the employees in efforts to improve their creativity. The managers also sought to improve their entrepreneurship and innovation levels by adapting their strategies to market needs. An interesting issue in the analysis is that $14.4 \%$ of the respondents indicated that they did not have any strategies for entrepreneurial development. The employees in terms of their effectiveness evaluated the motivational strategies adopted by the organisation. 
Table 9 Strategies for entrepreneurship development

\begin{tabular}{lccc}
\hline Strategy & $N$ & $\%$ & Cumulative \% \\
\hline Entrepreneurship training & 21 & 11.6 & 11.6 \\
Rewards and incentives & 41 & 22.7 & 34.3 \\
Contests for the employees & 34 & 18.8 & 53 \\
Adapt management to market needs & 31 & 17.1 & 70.2 \\
Considering creativity in hiring and HR strategies & 28 & 15.5 & 85.6 \\
None & 26 & 14.4 & 100 \\
\hline
\end{tabular}

The strategies adopted by the views of the respondents about their effectiveness as well as their outcomes in promoting entrepreneurship indicate a strong focus on people management. The views presented by the respondents indicate that HR management strategies and motivation through intrinsic and extrinsic means are highly effective in enhancing entrepreneurship among the employees (Table 10). Only $40.4 \%$ of the sample highlighted the entrepreneurship strategies as being effective with $18.8 \%$ being indifferent while the remaining $40.9 \%$ thought the strategies were ineffective (Table 10). As a result, the findings from this study support the second hypothesis developed for the research which state that 'employee management and motivation strategies are the most effective in improving entrepreneurship in the Irbid Governorate'.

Table 10 Rating on the effectiveness of the motivational strategies by HR

\begin{tabular}{lccc}
\hline Rating & $N$ & $\%$ & Cumulative \% \\
\hline Very low & 38 & 21 & 21 \\
Low & 36 & 19.9 & 40.9 \\
Medium & 34 & 18.8 & 59.7 \\
High & 49 & 27.1 & 86.7 \\
Very high & 24 & 13.3 & 100 \\
\hline
\end{tabular}

\subsection{Effect of privatisation and commercialisation on entrepreneurship}

Privatisation has been indicated as mechanism that can aid the public sector to align their strategy for being competitive. $43.1 \%$ of the sample rated privatisation high suggesting it is very significant while $35.4 \%$ rated it low which indicated that it not important, $21.5 \%$ of the respondents were indifferent in their views (Table 11).

Table 11 Relevance of privatisation to entrepreneurship

\begin{tabular}{lccc}
\hline Rated relevance & $N$ & $\%$ & Cumulative $\%$ \\
\hline Very low & 21 & 11.6 & 11.6 \\
Low & 43 & 23.8 & 35.4 \\
Medium & 39 & 21.5 & 56.9 \\
High & 44 & 24.3 & 81.2 \\
Very high & 34 & 18.8 & 100 \\
\hline
\end{tabular}


Based on these responses, the perception of public sector employees is that privatisation improves the outcomes for the public sector by introducing private sector approaches of people management in the public institutions. Thus, the third hypothesis of the study was supported by the research findings. The market focus and profit incentives were not highlighted as significant in motivating the development of more efficient organisations in terms of innovation and entrepreneurship.

The effect of commercialisation and privatisation on entrepreneurship mostly involved HR related developments. 26\% highlighted more effective HR management as being the most important effect followed by enhancement of the motivational strategies and application of efficient talent management (Table 12).

Table 12 Effect of privatisation and commercialisation on entrepreneurship

\begin{tabular}{lccc}
\hline Effect & $N$ & $\%$ & Cumulative \% \\
\hline Increasing market focus & 23 & 12.7 & 12.7 \\
More effective HR mgt & 47 & 26 & 38.7 \\
Profit incentives & 33 & 18.2 & 56.9 \\
More efficient motivation strategies & 41 & 22.7 & 79.6 \\
Effective talent management & 37 & 20.4 & 100 \\
\hline
\end{tabular}

\section{Discussion}

We found that entrepreneurship within the public sector in Jordan was very low, which indicated that there is a difference in the perceptions of its importance and its relevance to a growing economy and to advancing service delivery and productivity. This similar finding was shown by Kim (2010). Our study shows that their entrepreneurship activity within public sector is driven by incentives and rewards and employee development which are HR and management related activities. Moreover, participants were inclined to believe that any initiatives towards commercialisation and privatisation were mostly involving HR developments. This suggests that there is an important role that leadership plays in inspiring entrepreneurship within the public sector. Unlike private sector, individual working within the public sector need to be innovative in the way they conduct their activities in order to deliver better quality services to the citizens, and to study and respond to changes in the market. This is a form of entrepreneurship activity that can be introduced within government institutions (Hisrich and Al-Gabbagh, 2013). The relevance of political pressure and the misalignment with market goals or forces has been suggested by Tosterud (2002) and others. Unlike other studies such as Klein et al. (2009) that have highlighted the importance of bureaucracy as a key hindrance of entrepreneurial success in public organisation, our study shows that the major hindrance was not so much the bureaucracy but rather the misalignment of goals between politics and economy, and the lack of incentives, supporting the views of Tosterud (2002).

Entrepreneurial activity requires some form of risk taking behaviour, especially since it is likely that there is little known or pre-existing knowledge about several drivers in the market (Ramadani et al., 2015). However, if there is support for the entrepreneurial activity in government or within the organisation, then the threats are minimised. In the context of Jordan, there are well established mechanisms that support entrepreneurship 
which includes funding and support to enable growth (Dana, 2000; Caputo et al., 2016). According to Ramadani et al. (2015), having support from institutional environments of a country is important to contribute to the entrepreneurial activities especially when individuals know that their creativity and ideas have potential to be supported financially to enable progress of start-ups and other ventures (see also Caputo et al., 2016). Recent work by Caputo et al. (2015) suggests that most youth prefer to join established companies and government, avoiding start-ups and new ventures, while most of those who studied abroad are more prone to join a start-up or start one. This supports the idea that there is limited risk taking behaviour among the youth. In our sample, participants were of the view that only experienced staff, those who had interest public service and those who had prior work experience in the private sector were more likely to be innovative than to be entrepreneurial. Considering that the majority of the sample population for this study were young and had less than 5 years work experience, it is more understandable that their entrepreneurial activities were limited. In Jordan, youth are employed by government departments mostly and often straight out of graduation (Caputo et al., 2015). This study sample was reflective of what is often observed within public sector which employs the most of the youth. With increasing unemployment, the population is leaning on the entrepreneurship drive of individuals, and with the support given by the royal family opportunity for entrepreneurship within the private sector is very high (Dana, 2000; Kearney et al., 2008; Hisrich and Al-Gabbagh, 2013).

The Jordanian private sector functions like other civil services whose focus is on the development of services that are essential to the public. These issues result in these organisations having a focus that is different from that of the private sector. This has played a major role in influencing how they operate including the strategies adopted for responding to customer needs. The management of public institutions requires the implementation of effective programs for addressing the needs of the public through consideration of market trends and related issues. The focus on the different programs applied in the public sector is to improve service delivery and address the expectations of the public through changes in processes, cost management and efficiency in providing the services. This research indicates a relatively low focus in the Jordanian public sector organisations to motivate entrepreneurship and innovation. While the employees have positive views about the relevance of entrepreneurship, they differ in how they see the environment in promoting innovation. Similar findings were shown in the report by JYES and Konrad Adenauer Stiftung (2015) on the state of entrepreneurship in Jordan. Their survey indicated that the challenges facing the government sector in providing adequate services to the public are associated with the difficulties in harnessing the creativity and innovativeness of employees. A key recommendation that can be derived from this research is that administrators need to develop strategies for managing their human resources more effectively. They have to focus on managing talent and attracting creative employees to their organisations. This is critical in developing an organisational culture that is appropriate for creativity and acceptance of new ideas that are presented by the creative employees. Other recommended strategies that could enhance innovativeness and entrepreneurship for the public sector include developing appropriate incentives for the employees and the managers in the organisation. This would be effective in developing strong incentives for people to be creative and innovative in developing solutions. 
Innovation is the driver of performance (Ramadi et al., 2017), and innovative ideas can be promoted and supported through appropriate incentives and investment in those entrepreneurial employees. In general, in the public sector it may be easier to venture out from using novel ideas to create new businesses, but there may be challenges within the public sector to drive corporate entrepreneurship, especially when there is no support (Ramadani et al., 2017). The role of ICT as a facilitator of innovation and driver $\mathrm{f}$ entrepreneurship within the public sector still needs to be investigated. Considering the potential and opportunities provided by the established ICT sector in Jordan, there is more opportunity to develop corporate entrepreneurship. The issue of political and economic goals being misaligned is another major challenge to entrepreneurship. This challenge could be addressed through more efficient alignment of the organisational goals and elimination of political influence. This would enable the firms to focus on market conditions or addressing their customers' needs without distortion from the political leaders.

\section{Conclusions}

A sample of 181 employees of a Jordanian public service sector organisation were asked to rate their views on different aspects of entrepreneurship. Generally, the respondents thought that the rate of entrepreneurship in public organisations was low but the respondents themselves thought it was important and relevant. Experienced staff members were seen as the most enterprising employees. Changes in service process and efficiency were seen as the two main areas that could contribute most to innovation. Attracting creative people and the acceptance of new ideas were seen as the best ways that management could enhance entrepreneurship. The misalignment of goals between the organisation and politicians was seen as the greatest hindrance. Employee rewards and incentives were seen as the best ways of developing entrepreneurship. There were mixed results of the effectiveness of current motivational strategies and strong suggestion that better HR management was a key to more innovation.

\section{Implications and recommendations}

The findings of this study suggest that there are challenges to develop entrepreneurship within the public sector of Jordan. Although it is viewed as an important part of economic development, there is a wide belief that it is challenging and risky, and that more is needed to be done in order to inspire this activity within the public sector. The workers within the public sector are young and experienced, and less likely to take risks to come up with innovative and creative ideas. To enable this, HR and management need to come up with strategies to increase employee engagement particularly in coming up with new and innovative ways to solve challenges in the public sector. Inspiring the integration of ICT can activate innovation, particularly among the youth who comprised the majority of the workers and who are in touch with global change.

Management practices play a critical role in promoting and hindering entrepreneurship. Appropriate incentives and rewards, professional development opportunities and establishing diverse teams that incorporate all ages and experiences is likely to inspire creativity among employees. Management has a key role to play in 
developing entrepreneurship activities and behaviour within the public sector. These opportunities can be enhanced by allocating appropriate resources and time to also enable participants to engage or identify opportunity. For example, participants indicated that HR should spend appropriate time in identifying staff that are innovating and creative during the hiring process. This observation was also found by Kearney et al. (2008) who suggest that allocation of appropriate resources is a crucial driver of entrepreneurship or corporate entrepreneurship behaviour. However, this study also suggests that HR and management have a crucial role to play in identifying entrepreneurial processes that increase entrepreneurship activity within public organisations.

In their review, Caputo et al. (2016) indicate that there is a high number of youth unemployment and the vehicles that take them up such as government and military have reached their capacity. This is indicative that the public sector is remaining stagnant in its approach to address the challenges of the citizens and need to allow for more entrepreneurial activities similar to what is observed in the public sector. Therefore, it remains up to the management of public institutions to align the goals of the nation as directed by the royal family with the needs of the society in order to create more opportunities and to increase economic growth.

\section{Limitations}

Limitations of the study include a small sample and the requirement of single answers to complex questions. Further research within the Jordanian public sector and other public sectors will inform whether the employee perceptions presented here are robust and in what way they might influence the management and operations of public sector organisations. Gender effects were not investigated, when females comprised a slightly larger proportion of the study participants.

\section{Future research directions}

The goal of the Jordanian government is to increase the level of innovation and entrepreneurship within the country, as they view this to be the centre of economic growth and development. Future research should investigate the cultural contexts which drive entrepreneurial activity, especially since the majority of the population is very young and unemployment rates are increasing. The Islamic religion has been suggested to be one that drives entrepreneurship and self-support with the aim to contribute towards innovation building. Therefore, it is imperative that the cultural and religious context driving entrepreneurship differ under the contexts of private and public sector employees. We also suggest that considering opportunities available for entrepreneurial activities for young people and for women, whether there are differences in perceptions of entrepreneurship opportunities within the public and private sectors or not. In the current study, participants highlighted that they believe entrepreneurship is important to economic growth, but the contexts of gender and age were not very well explored and so more work is needed to understand if women and youths in public sector view the availability of entrepreneurship activity differently compared to those who are in the 
private sector, and whether this may influence their risk taking behaviour in coming up with novel ways to solve challenges faced by the society.

\section{References}

Andrew, D.P.S., Pedersen, P.M. and McEvoy, C.D. (2011) Research Methods and Design in Sport Management, Human Kinetics, Champaign, IL.

Audretsch, D.B., Boente, W. and Tamvada, J.P. (2007) Religion and Entrepreneurship, Jena Economic Research Papers, No. 2007,075 [online] http://hdl.handle.net/10419/25667 (accessed 1 May 2017).

Benz, M. and Frey, B.S. (2007) 'Corporate governance: what can we learn from public governance?', Academy of Management Review, Vol. 32, pp.92-104.

Caputo, A., Lombardi, R., Akeel, F., Almallah, H., Dakkak, B. and Qubbaj, N. (2015) 'Youth employment in start up ventures in Jordan: an exploratory study', International Journal of Entrepreneurship and Small Business, Vol. 28, No. 4, pp.468-491.

Caputo, A., Mehtap, S., Pellegrini, M.M. and Al-Refai, R. (2016) 'Supporting opportunities for female entrepreneurs in Jordan', International Journal of Entrepreneurship and Small Business, Vol. 27, Nos. 2/3, pp.384-409.

Creswell, J.W. (2014) Research Design: Qualitative, Quantitative and Mixed Methods Approaches, Sage Publications, Thousand Oaks.

Currie, G., Humphreys, M., Ucbasaran, D. and McManus, S. (2008) 'Entrepreneurial leadership in the English public sector: paradox or possibility?', Public Administration, Vol. 86, No. 4, pp.987-1008.

Dana, L. and Dana, T. (2005) 'Expanding the scope of methodologies used in entrepreneurship research', Int. J. Entrepreneurship and Small Business, Vol. 2, No. 1, pp.79-88.

Dana, L.P. (1993) 'Environment for entrepreneurship: a model of public policy and economic development', The Journal of Entrepreneurship, Vol. 2, No. 1, pp.73-86.

Dana, L.P. (2000) Economies of the Eastern Mediterranean Region: Economic Miracles in the Making, World Scientific, London, UK.

Dana, L.P. (2009) 'Religion as an explanatory variable for entrepreneurship', Entrepreneurship and Innovation, Vol. 10, No. 2, pp.87-99.

Gergurri-Rashiti, S., Ramadni, V., Abazi-Alili, H., Dana, L. and Ratten, V. (2017) 'ICT, innovation and firm performance: the transition economies context', Thurnderbird International Business Review, Vol. 59, No. 1, pp.93-102.

Heinonen, J. (2003) Entrepreneurship in Public Sector Organizations [online] $\mathrm{http}: /$ citeseerx.ist.psu.edu/viewdoc/download?doi=10.1.1.199.5050andrep=rep1 andtype=pdf (accessed 28 March 2017).

Hisrich, R.D. and Al-Dabbagh, A. (2013) Governpreneurship: Establishing a Thriving Entrepreneurial Spirit in Government, Edward Elgar, UK.

JYES and Konrad Adenauer Stiftung (2015) Research Study on Strengthening Small and Medium Enterprises in Jordan [online] http://www.kas.de/wf/doc/kas_41279-1522-2-30.pdf?1505 10112915 (accessed 28 March 2017).

Kearney, C., Hisrich, R. and Roche, F. (2008) 'A conceptual model of public sector corporate entrepreneurship', International Entrepreneur Management Journal, Vol. 4, No. 4, pp.295-313.

Kearney, C., Hisrich, R.D. and Roche, F. (2009) 'Public and private sector entrepreneurship: similarities, differences or a combination?', Journal of Small Business and Enterprise Development, Vol. 16, No. 1, pp.26-46.

Kim, Y. (2010) 'Stimulating entrepreneurial practices in the public sector: the roles of organizational characteristics', Administration and Society, Vol. 42, No. 7, pp.780-814. 
Klein, P.G., Mahoney, J.T., McGahan, A.M. and Pitelis, C.N. (2009) Toward a Theory of Public Entrepreneurship [online] https://business.illinois.edu/working_papers/papers/09-0106.pdf (accessed 28 March 2017).

Matthews, J. (2010) Entrepreneurship in Public Sector: New Possibilities? QUT Business School [online] http://eprints.qut.edu.au/71108/2/Matthews_-_Entrepreneurship_in_the_public sector_-_ACERE.pdf (accessed 28 March 2017).

Morris, M.H. and Jones, F.F. (1999) 'Entrepreneurship in established organizations: the case of the public sector', Entrepreneurship Theory and Practice, Vol. 24, No. 1, pp.71-91.

Radnor, Z. and Noke, H. (2012) Entrepreneurship in Public Services: Understanding its Role in Change, Academy of Management Meeting, Boston.

Ramadani, V., Abazi-Alili, H., Dana, L., Rexhepi, G. and Ibraimi, S. (2017) 'The impact of knowledge spillovers and innovation on firm-performance: findings from the Balkans countries', International Entrepreneur Management Journal, Vol. 13, No. 1, pp.299-325.

Ramadani, V., Dana, L., Ratten, V. and Tahiri, S. (2015) 'The context of Islamic entrepreneurship and business: concept, principles and perspective', International Journal of Business and Globalisation, Vol. 15, No. 3, pp.244-261.

Short, J., Moss, T. and Lumpkin, G. (2009) 'Research in social entrepreneurship: past contributions and future opportunities', Strat. Entrepreneurship J., Vol. 3, No. 2, pp.161-194.

Spencer, J.W., Murtha, T.P. and Lenway, S.A. (2005) 'How governments matter to new industry creation', Academy of Management Review, Vol. 30, No. 2, pp.321-337.

Taamneh, M., Athamneh, S. and Al Nsairat, B. (2017) 'The effect of administrators' work-related ethics on practicing human resource management functions at Jordanian universities', Int. J. Public Sector Performance Management, Vol. 3, No. 3, pp.337-354.

Tosterud, R.J. (2002) Entrepreneurship and the Public Sector [online] http://www.jgbm.org/ page/15\%20\%20Robert\%20J.\%20Tosterud.pdf accessed 28 March 2017).

Zerbinati, S. and Souitaris, V. (2005) 'Entrepreneurship in the public sector: a framework of analysis in European local governments', Entrepreneurship and Regional Development, Vol. 17, No. 1, pp.43-64. 